\title{
Reports
}

\section{Chemical Innovation and New TSCA: The Good, the Bad, and the Evolving}

Lynn L Bergeson and Richard E Engler*

New chemical innovation is not as celebrated as innovation in electronics, materials, software, or other sectors, but it is every bit as important. Many believe, as do we, that new chemical innovation is essential to achieving sustainable development. For this reason, a close look at the 2016 amendments to the Toxic Substances Control Act (TSCA) and the U.S. Environmental Protection Agency's (EPA) implementation of them offers valuable insights into whether the new U.S. industrial chemical management law and EPA policy initiatives implementing it are aligned with this goal. This article discusses EPA's implementation of the TSCA amendments as they relate to new chemical innovation and highlights EPA policy positions and institutional practices that EPA should reconsider to align more closely with the goal of more sustainable new chemical technologies.

\section{Chemical Innovation Today}

Most new chemicals today are products intended to achieve particular, and often discrete, functions and market uses. Many products are not intended for continuous production, but are more likely to be highvalue, low-volume products that are batch produced. Most new chemical products are not entirely new. They are intended to improve on the functionality and performance of existing chemicals by commer-

DOI: $10.21552 / \mathrm{icrl} / 2019 / 4 / 5$

* Lynn L. Bergeson is the Managing Partner of Bergeson \& Campbell, P.C. $\left(B \& C^{\circledR}\right)$, a Washington, D.C., law firm focusing on conventional, nano, and biobased chemical, pesticide, and other specialty chemical product approval and regulation; environmental, health, and safety law; chemical product litigation; and associated business issues. Richard E. Engler, Ph.D., is the Director of Chemistry with B\&C and a 17-year veteran of EPA. cializing new chemical avatars that exhibit better processing options and are more efficient, more efficacious, and less toxic. Many improvements seen with new chemicals are incremental, and they frequently have only a limited period of commercial success as, over time, 'new and improved' substances replace their previously new chemical predecessors, creating a continuous cycle of chemical innovation.

Increased product efficiency also translates into less material being used (reducing manufacturing costs) and less material being released into the environment (reducing disposal or treatment costs), which is the essence of pollution prevention. The availability of better processing options, including equal or improved performance at lower temperatures, leads to reduced energy usage and potentially safer work environments. These are all goals TSCA was intended to achieve.

Importantly also, chemical innovation today is driven by societal forces that are qualitatively and quantitatively different from what existed four decades ago when TSCA was first enacted. Mindful of tort and product liability, evolving and increasingly stringent stewardship standards, and private codes of conduct that significantly exceed legally enforceable limits, chemical innovators and manufacturers today are driven by the commercial imperative to diminish hazard and thus risk. The everpresent scrutiny of social media holds companies immediately accountable for missteps in the court of public opinion, and there is relentless pressure on corporate entities to diminish their environmental footprints.

\section{TSCA New Chemical Review}

As a preliminary matter, it is important to emphasize TSCA's North Star -- the explicit national policy ar- 
ticulated in TSCA Section 2 and unchanged since 1976 to review new chemicals:

TSCA Section 2(b)(3) reads, in pertinent part: ' $[\mathrm{i}] \mathrm{t}$ is the policy of the United States that ... authority over chemical substances and mixtures should be exercised in such a manner as not to impede unduly or create unnecessary economic barriers to technological innovation while fulfilling the primary purpose of this Act.'

EPA must under TSCA decide and act in compliance with the statutory requirements, but it must do so in a manner that does not create undue burden on innovation or barriers to innovative technologies.

Under both old and new TSCA, chemicals listed on the TSCA Inventory are considered 'existing' chemicals. Chemicals that are not listed on the TSCA Inventory are considered 'new' chemicals, and chemical manufacturers must notify EPA under TSCA Section 5 prior to manufacturing, processing, or importing new chemicals, or qualify for an exemption from doing so. Section 5 notices include premanufacture notifications (PMN) and various exemption notifications. For readers familiar with the PMN process, they will appreciate that it is not an easy or intuitive one; can take 6-12 months to complete (and potentially longer), a time well in excess of the statutory 90-day review period; can be costly if done correctly; is sometimes unpredictable in timing and outcome; and does not always end favorably.

Under TSCA pre-Lautenberg, EPA conducted its scientific and regulatory analysis and, if EPA did not identify an issue to a PMN submitter and take action within the 90-day statutory review period, EPA would 'drop' the case from further review and, after the 90day review period expired, the submitter was permitted to begin commercial manufacture, processing, or import of the chemical substance for which the notification was submitted, followed by submission of a Notice of Commencement (NOC). Although not required by old TSCA, EPA paid close attention to completing any needed actions within the 90-day time frame for review. Based on our experience, EPA seldom missed the deadline due to error. In most of these cases, EPA and the submitter were able to negotiate an approach that kept the case within the PMN regulatory time frame. The submission of the NOC was (and continues to be) the act that placed the chemical substance on the chemical Inventory, converting the legal status of the substance to that of an existing chemical.

In hindsight, the elegance and efficiency of the pre-Lautenberg Section 5 process was underappreciated. The process included, and continues to include, the Chemical Review and Search Strategy (CRSS) team meeting that reviews the chemistry profile of the new chemical substance (ie, chemical identity and structure, physicochemical properties, and analogs); the Structure Activity Team (SAT) team meeting that reviews and establishes a rating for the likely hazards each new chemical substance may present to health or the environment, as well as the substance's expected environmental fate; evaluation of the degree of the new chemical substance's potential human exposures (worker and general public) and environmental releases; a 'Focus' meeting, where EPA characterized the risk and decided whether the new chemical substance would, might, or was not likely to present risk to health or the environment; and if at the Focus meeting, EPA decided that a PMN chemical substance may present risks, but those risks are not adequately characterized, an in-depth 'standard review' would compile a more complete risk characterization to inform EPA's risk determination and the most appropriate risk management option.

Questions often arose in these review stages, and EPA would contact the submitter to seek additional information. EPA routinely reviewed risks to workers and other potentially exposed populations, as well as ecological risks. When regulatory issues were identified, EPA and the submitter negotiated and agreed on the terms of a consent order under Section $5(\mathrm{e})$ and/or EPA implemented a Significant New Use Rule (SNUR) to require advance notification to EPA of any 'significant new uses' (conditions of use) that EPA foresaw might lead to an unreasonable risk.

EPA's review of new chemicals often resulted in the imposition of workplace or environmental release limitations and other restrictions under Section 5(e) orders on the PMN submitter, downstream processors, and on occasion, users of the new chemical. Alternatively, or in addition, EPA would promulgate SNURs to compel notification of significant new uses from these same types of entities prior to undertaking the identified significant new use. A 'significant new use' frequently did (and still does) not involve a 'new' use in the commonly understood way, but rather refers to some chemical-specific re- 
striction or limitation that, if exceeded, triggers a Section 5 notification (for example, use above a certain volume or in a particular physical form). A SNUR establishes a requirement to notify EPA 90 days before commencing any activity that the SNUR defines as a 'significant new use.' In response to a Significant New Use Notification (SNUN), EPA reviews the proposed application using the same paradigm EPA uses for new chemicals and issues a Section $5(\mathrm{e})$ order to require testing, control potential unreasonable risks presented by the significant new use, modify the existing SNUR, or some combination of all three.

As part of this process under old TSCA, EPA routinely identified 'potential new uses of the chemical (other than those reviewed as part of the PMN) ${ }^{1}$ as such reviews provided the basis for the 1,557 non-5(e) SNURs EPA issued under TSCA prior to Lautenberg ${ }^{2}$. Pre-Lautenberg, some 40,00o new chemicals were reviewed by EPA, and regulatory action was taken on approximately ten to 15 percent of new chemicals, meaning that between 85 and 90 percent could proceed without restriction to commencement of manufacture and commercialization. A 'NOC' of manufacture or import must be submitted to EPA within 30 days of first manufacture or import. Based on our prior experience at EPA, NOCs were typically received on 50 percent or somewhat fewer of the submitted PMNs.

EPA's new TSCA Section 5 review process disallows consideration of costs or other non-risk factors in determining whether the new chemical presents an unreasonable risk. New TSCA also now explicitly requires EPA to consider unreasonable risks to 'potentially exposed or susceptible subpopulations' (including workers, infants, children, and others) identified as relevant by EPA under the 'conditions of use' in making certain of the determinations under Section 5, although EPA arguably routinely did so under old TSCA.

The first of the determinations (TSCA Section 5(a)(3)(A), 15 U.S.C. Section 2604(a)(3)(A)) that EPA can make is that the new chemical 'presents' an unreasonable risk of injury to health or the environment, in which case EPA must then regulate the new

1 EPA, 'Statistics for the New Chemicals Review Program under TSCA' (2017) Snapshot.

2 Statistics for the New Chemicals Review Program under TSCA. chemical under Section $5(\mathrm{f})$ 'to the extent necessary to protect against such risk' and promulgate a significant new use rule (SNUR), or publish a statement explaining why it is not initiating such a rulemaking. TSCA Section 5(f)(4), 15 U.S.C. Section 2604(f)(4). Such determinations are rare for new chemicals because it is seldom the case that EPA is sufficiently confident in both the available hazard and exposure data to make such a definitive finding.

The second determination (TSCA Section 5(a)(3)(B), 15 U.S.C. Section 2604(a)(3)(B)) that EPA can make is that the information available is insufficient for a reasoned evaluation of the health and environmental effects; or that in the absence of sufficient information for an evaluation, the manufacture, processing, distribution in commerce, use, or disposal may present an unreasonable risk of injury to health or the environment; or that the new chemical is or will be produced in substantial quantities, and the substance enters or may reasonably be anticipated to enter the environment in substantial quantities, or there is or may be significant or substantial human exposure to the new chemical. Because this alternative consists of a series of 'or' statements, if any of these determinations is satisfied, EPA must then issue an order to regulate the new chemical under Section 5(e) to the extent necessary to protect against an unreasonable risk of injury, without consideration of costs or other nonrisk factors, including unreasonable risks to potentially exposed or susceptible subpopulations identified as relevant by EPA under the conditions of use. EPA must also then either promulgate a SNUR or explain why it is not initiating such a rulemaking. TSCA Section $5(\mathrm{f})(4), 15$ U.S.C. Section 2604(f)(4).

The third determination (TSCA Section $5(\mathrm{a})(3)(\mathrm{C})$, 15 U.S.C. Section 2604(a)(3)(C)) that EPA can make is that the new chemical is not likely to present an unreasonable risk of injury to health or the environment. In such cases, the PMN submitter may immediately commence manufacture, import, or processing. New TSCA requires EPA to publish a statement of its finding (TSCA Section 5(g), 15 U.S.C. Section 2604 (g)), which EPA publishes on its website and in the Federal Register. TSCA Section 5(h), which concerns exemptions from PMN notification, has been retained with generally conforming changes in new TSCA. They include test market exemptions (TME) and low-volume exemptions (LVE). 


\section{Implementation Disarray}

Despite EPA's best efforts, its implementation of the Section 5 revisions over the past three years has been challenging for new chemical innovators. There are several reasons why. First, in its early implementation, EPA initially embraced an overly broad interpretation of 'reasonably foreseen' to include virtually any imaginable set of conditions, including those based on mere speculation, as opposed to what we believe Congress intended, namely a plausible (ie, 'reasonably foreseen') extension of or addition to the conditions of use as described in the PMN. Based on our experience, particularly at the outset of implementation of Lautenberg, EPA decisions also often simply conflated assessment of hazard (toxicity) and risk (a function of both hazard and exposure), with the result that virtually any new chemical with an identified 'potential hazard' was regulated as if it presented an unreasonable risk. If EPA identified a potential hazard, EPA then assumed that some condition of use could exist that would lead to an exceedance of a concern level, without considering whether such condition of use was plausible or likely as defined by Lautenberg.

Second, EPA continues to overlook factual hazard and exposure data and information contained in the PMN. EPA often instead uses modeled results from structure-activity relationship (SAR) analysis and/or chemical analogs to assess hazards and EPA-preferred exposure models and assumptions that yielded unreasonably conservative or simply incorrect hazard, exposure, and risk assessments that compelled the application of regulations that, not infrequently, represented commercially devastating overreach. EPA would only use a submitter's estimate for releases or exposures if those values were more conservative (ie, higher exposures and greater releases) than EPA's conservative assumptions. In this paradigm, there was essentially no reason for a submitter to include measured exposure or other information relating to conditions of use. This outcome is not aligned with EPA's frequently made recommendation to include as much information about the conditions of use as possible in a PMN, a recommendation now included in EPA's Points to Consider document, a document EPA as recently as December 20, 2019, reissued for comment.

The result has been painful. New chemical review is characterized by lengthy delays (although EPA has improved and shortened these delays) as submitters struggle to understand and address EPA's concerns and, in our view, overregulation. This situation has significantly reduced the volume of new chemical innovation entering the market. This problem is most readily seen in the small number of post-Lautenberg PMN chemicals that have commenced manufacture since the new law entered into effect in June 2016.

EPA's departure from its previous practices is due principally to its interpretation of what is 'not likely to present unreasonable risk' under the reasonably foreseeable conditions of use. There are several points in this standard that require EPA to make a judgment: How unlikely does a circumstance need to be to be deemed as 'not likely,' what is an 'unreasonable risk,' and what is a 'reasonably foreseeable' condition of use? What is 'likely' can be addressed by EPA using its standard conservative models (the Sustainable Futures tools). If EPA's standard conservative estimates do not lead to EPA predicting releases or exposures that lead to a concern, EPA could conclude that such exceedances are 'not likely.'

'Unreasonable risk' is not a term new to TSCA, but neither has it been defined or its boundaries tested under old or new TSCA. An example of a hazard EPA identified that it believed presented an unreasonable risk includes mild-to-moderate eye irritation. There are cases in which EPA identified concerns for eye irritation and then proposed requiring workers to use protective eyewear such as goggles. It is not always clear how eye irritation is determined to be an unreasonable risk. Nearly everything is irritating to eyes, even water. This standard would require that EPA require eye protection for everything that has not been tested and shown to not irritate eyes. In addition, eye irritation is an end point against which we fully expect users to opt to protect themselves. If an activity causes an eye exposure that leads to irritation, it is likely that the user would choose to use eye protection, regardless of whether such protection is required by TSCA, or to use the substance in a manner to minimize the chance for eye exposure. Mild-tomoderate eye irritation is not an unreasonable risk, nor is it a risk that requires a TSCA consent order to mitigate.

'Reasonably foreseeable condition of use' is a new term under Lautenberg, but a similar term has been in use under old TSCA for some time: 'reasonably anticipated.' In the polymer exemption criteria, 'rea- 
sonably anticipated' is defined, in relevant part, as what 'a knowledgeable person would expect a given physical or chemical composition or characteristic to occur.' 4 O C.F.R. Section 723.250 (b). EPA also defined 'reasonably foreseeable' as being based on information, knowledge, or experience in its risk evaluation rule. 82 Fed. Reg. 33726 (July 20, 2017). Neither of these definitions aligns with the concept of 'any possible' conditions of use.

\section{Innovation Implications and How to Evolve the Program}

What do these regulatory and policy changes mean for innovation? In short, there has been a significant drop in the rate of commenced cases, from roughly 50 percent under old TSCA, to around 20 percent under new TSCA after the first two years following enactment. We understand that the trend has continued in 2019, and may well into 2020. In our view, this drop is evidence that the new chemicals process implemented under new TSCA is having an adverse effect on the commercialization of new chemicals. EPA and chemical innovators may wish to consider several measures to improve the process, hasten the innovation and commercialization of new chemicals, and achieve Congress's goals in enacting TSCA.

\section{Revise the New Chemicals Framework Document}

As mentioned above, on December 20, 2019, EPA released its revised draft New Chemicals Decision Making Framework, following a public stakeholder meeting on December 10, 2019, and comment EPA received on a 2017 version of the document. Based on a preliminary review of the document, EPA has made important changes and provided much-needed clarity on the new chemical review process. Comments are to be submitted by mid-February 2020 .

Importantly, EPA includes in the draft Framework document a detailed elucidation of how EPA determines conditions of use as intended, known, and reasonably foreseen. Similarly, EPA describes with particularity how it interprets 'insufficient information' and 'unreasonable risk of injury to health or the environment.' As helpful as the draft is, inclusion of examples and/or case studies would be preferred. EPA offers other important changes and clarifications that help, and on the whole the new draft is an improvement over the 2017 version. Stakeholder comment can be expected to be vigorous.

\section{Review and Consider Actual Data over Modeled Results}

EPA should consistently review and consider the data and information submitted with PMNs and give this information priority over modeled results. Actual data should only be excluded when they are determined to be unreliable or inapplicable for some specified reason.

\section{Submitters Should Significantly Improve the Quality of Their Submissions}

We have found that some have been slow to grasp the new normal of new TSCA. Notifications must be well crafted, detailed, and scientifically defensible documents. Gone are the days of hastily preparing a PMN and hoping for the best. Under the law, submitters no longer have the benefit of the doubt, and the burden is on the submitter to describe how a new chemical does not pose an unreasonable risk. This work takes time, energy, and close attention to detail. Consult with experts and do it right. Note also that the EPA fee for processing a PMN is considerably higher than it was.

\section{Get over Your Aversion to SNURs}

Speaking of the new normal, SNURs are part of the new chemical landscape and no longer the exception that makes the rule. SNURs are not necessarily commercially bad news, and great care should be taken to explain the role of a SNUR in your company's chemical stewardship program. SNURs should not be demonized, as they are not going away. Help your supply chain understand the effect of a SNUR and how downstream customers probably already comply with the restrictions included under a SNUR. This communication can go a long way in disabusing a customer of the true impact of a SNUR and lessen their anxiety about a SNUR's presumed commercial consequences. 


\section{Conclusion}

Stakeholders recognize that new chemical innovation is essential to achieving sustainable prosperity and to enabling technologies that can help to meet the challenges of the 21st century. TSCA stakeholders are urged to advocate for changes in the new chemical review process to ensure that TSCA's national policy of fostering chemical innovation is more consistently realized. Submitters need to do their part and prepare compelling and well-supported notifications that give EPA every incentive to review the data efficiently and determine that new chemical innovation can be commercialized with a minimum of regulation. We applaud EPA's recent efforts to revise the Framework document, and we urge EPA expeditiously to make similar practice corrections to support the chemical innovation process. 